\title{
Estratégia metacognitiva para repensar os níveis representacionais envolvidos numa transformação química
}

\author{
Solange Wagner Locatelli ${ }^{1}$
}

\begin{abstract}
RESUMO
Por meio dessa pesquisa, pretendeu-se compreender como que oito graduandos de uma universidade pública se apropriam dos níveis representacionais ao proporem explicações para a transformação química envolvida na combustão do metano. Para isso, os alunos tinham que elaborar um texto para explicar essa reação química, bem como responder a um questionário no início e no final do processo. A pesquisa foi de cunho qualitativo, apoiando-se na análise textual discursiva para a organização dos dados, em que unidades de análise foram geradas a partir dos textos produzidos. Os resultados indicaram uma prevalência das explicações em nível macroscópico, sendo que o nível submicroscópico foi menos considerado, bem como a transição entre os níveis, mesmo com alunos mais experientes. Isso evidencia a necessidade de uma retomada nas explicações envolvendo o triplete, de tempos em tempos, para uma melhor apropriação desse entendimento, uma vez que o mesmo não é espontâneo.
\end{abstract}

PALAVRAS-CHAVE: Níveis representacionais. Ensino de Química. Transformação química. Estratégia metacognitiva. Formação inicial.

Metacognitive strategy to rethink the representational levels involved in a chemical transformation

\footnotetext{
ABSTRACT

Through this research, it was intended to understand how eight undergraduates of a public university appropriate the representational

1 Doutora. Universidade Federal do ABC, Santo André, SP, Brasil. https://orcid.org/0000-0002-7639-6772. solange.locatelli@ufabc.edu.br.
} 
levels by proposing explanations for the chemical transformation involved in methane combustion. For this, students had to write a text to explain this chemical reaction, as well as answer a questionnaire at the beginning and end of the process. The research was qualitative, based on discursive textual analysis for data organization, in which units of analysis were generated from the texts produced. The results indicated a prevalence of explanations at the macroscopic level, with the submicroscopic level being less considered, as well as the transition between levels, even with more experienced students. This highlights the need for a return to explanations involving the triplet from time to time for a better appropriation of this understanding, since it is not spontaneous.

KEYWORDS: Representational levels. Chemistry teaching. Chemical transformation. Metacognitive strategy. Pre-service training.

Estrategia metacognitiva para repensar los niveles de representación involucrados en una transformación química.

\section{RESUMEN}

A través de esta investigación, se pretendía comprender cómo ocho estudiantes universitarios de una universidad pública se apropian de los niveles de representación al proponer explicaciones para la transformación química involucrada en la combustión de metano. Para esto, los estudiantes tuvieron que escribir un texto para explicar esta reacción química, así como responder un cuestionario al principio y al final del proceso. La investigación fue cualitativa, basada en el análisis textual discursivo para la organización de datos, en el que se generaron unidades de análisis a partir de los textos producidos. Los resultados indicaron una prevalencia de explicaciones a nivel macroscópico, siendo menos considerado el nivel submicroscópico, así como la transición entre niveles, incluso con estudiantes más experimentados. Esto resalta la necesidad de volver a las explicaciones que involucran al triplete de vez en cuando para una mejor apropiación de esta comprensión, ya que no es espontánea.

PALABRAS CLAVE: Niveles de representación. Enseñanza de la química. Transformación química. Estrategia metacognitiva. Formación inicial. 


\section{Introdução}

É fundamental ao professor considerar e organizar estratégias apropriadas para a sala de aula com vistas a aprimorar o aprendizado dos alunos, possibilitando o repensar constante de suas ideias, constituindo-se de estratégias metacognitivas. A metacognição envolve a supervisão, identificação e uma possível regulação, pelo próprio indivíduo, de seu processamento mental, o que Flavell (1976) definiu como monitoramento e autorregulação de processos cognitivos.

A Química é uma ciência pautada em modelos que visam explicar os fenômenos químicos, sendo uma tendência, hoje em dia, ter o foco na compreensão e reflexão dos processos, com menos ênfase na memorização. Freire, Talanquer e Amaral (2019) recomendam que o principal objetivo do Ensino em Química deveria ser a compreensão da natureza do pensamento químico, suas utilizações, bem como o impacto disso tudo em nossas vidas.

Considerar os níveis representacionais macroscópico, submicroscópico e simbólico, bem como a transição entre eles, pode auxiliar na compreensão das transformações químicas (JOHNSTONE, 1993), além de ajudar na previsão de tantos outros fenômenos. Assim, espera-se que os alunos, ao se depararem com esses conceitos, possam ter a oportunidade de construção e reconstrução de ideias.

Sendo assim, espera-se contribuir com essa pesquisa nesse sentido, partindo de uma reflexão proporcionada aos futuros professores de química, acerca dos níveis representacionais, por meio de uma estratégia metacognitiva, investigando-se as explicações conceituais propostas por eles, para se compreender as lacunas existentes nesse entendimento que é fundamental no Ensino de Química. Assim, foram investigadas as compreensões dos futuros professores de química sobre os níveis 
representacionais ao final de uma disciplina, procurando evidências acerca das transições realizadas ou não por eles com vistas a contribuir para futuros trabalhos e, sobretudo, na sala de aula. Pereira et al.(2018) investigando futuros professores de química em formação inicial concluiu que os saberes docentes se traduziram em saberes divididos em compartimentos com reduzida interação entre eles. Assim, uma retomada dos conceitos sempre pode se configurar de uma oportunidade de ressignificação.

Barke et al. (2019) investigaram professores de química interpretando transformações químicas considerando-se as partículas envolvidas no processo e constataram inúmeras concepções alternativas e a recomendação, feita por eles, é que isso seja retomado posteriormente com os educadores de forma a promover a reconstrução desses conceitos adequadamente. Pelo exposto, se justifica pesquisar sobre estratégias junto a esses profissionais que possibilitem a exteriorização dessas concepções, conforme afirmam Upahi e Ramnarain (2019, p.2, tradução nossa) quando dizem que "para alcançar o entendimento de química pelos alunos, há um amplo consenso na comunidade de Ensino de química acerca da importância e necessidade de integrar o ensino dos diferentes níveis representacionais em química e os recursos utilizados para a aprendizagem", o que evidencia uma lacuna ainda existente e, portanto, propícia a ser investigada com profundidade.

Numa universidade pública paulista é oferecida a disciplina de Práticas de Ensino de Química II (PEQ II), componente obrigatório ao licenciando em química, mas que é possível de ser cursada por qualquer aluno da universidade e em qualquer período (ano) da graduação, não havendo pré-requisitos. Nela, tem-se como objetivo a abordagem de alguns aspectos importantes na formação do professor de Química como, por exemplo, uma reflexão acerca dos níveis representacionais, com vistas a compreendê-los quanto às suas possibilidades e também limitações. Portanto, é fundamental que os futuros professores se apropriem adequadamente desses conceitos específicos da química. Particularmente, 
quanto a esse aspecto, a presente pesquisa objetivou investigar: Como futuros professores de Química se apropriam das explicações nos níveis representacionais ao relacioná-los a um fenômeno químico do cotidiano?

\section{Niveis representacionais}

Johnstone (1993) descreveu os níveis representacionais na compreensão da química, como um triângulo, sendo cada vértice os níveis macroscópico, submicroscópico e simbólico. Recomenda que para compreender química é necessário transitar nos três níveis e, ainda, que o ensino-aprendizagem está mais voltado para dois dos vértices, o macroscópico e o simbólico, sendo que o submicroscópico é o menos trabalhado.

Em 2009, foi publicado um livro tratando da representação triplete para o Ensino de Química, reunindo vários artigos sobre o tema de especialistas na área. No capítulo 1, Gilbert e Treagust (2009) fazem uma apresentação dos níveis. Embora sejam muitas as discussões sobre o que se considera em cada nível, utilizaremos aqui as que se alinham à pesquisa realizada, não havendo a intenção de restringir a discussão. Também adotaremos neste trabalho, a mesma denominação que Gilbert e Treagust (2009) para os níveis, quais sejam, macro (macroscópico), simbólico e submicro (submicroscópico).

Gilbert e Treagust (2009) sustentam que o nível macro refere-se aquele que é percebido pelos sentidos. Podemos conceber como o fenomenológico, aquele que, por exemplo, podemos ver, como a mudança de cor do repolho roxo para vermelho quando a ele adicionamos vinagre. Isso se deve às antocianinas que são pigmentos que mudam de cor conforme a acidez do meio. Rahayu e Kita (2010) trazem o nível macro como aquele experienciado no cotidiano pelas pessoas como, por exemplo, o enferrujamento de um prego de ferro. Resumindo, podemos dizer que o nível 
macro é a visualização da química em ação, é o que comumente é observado pelas pessoas.

Com relação ao nível submicro, Gilbert e Treagust (2009) definem como aquele que apresenta uma explicação qualitativa para o fenômeno, sendo consideradas nesse grupo, as entidades muitos pequenas como moléculas, átomos, íons, elétrons, etc. No exemplo da formação da ferrugem, teríamos íons de ferro interagindo com moléculas de oxigênio do ar para formar partículas de óxido de ferro (RAHAYU; KITA, 2010).

Adadan (2013) explica que um fenômeno químico pode ser representado tanto pelo nível macro como pelo submicro, residindo a diferença na escala que pode ser visível ou invisível. Entretanto cabe aqui enfatizar que o nível macro é concreto, é o fenômeno acontecendo, como por exemplo, um pedaço de madeira queimando, ele pode ser visto ou pode ser sentido (liberação de energia), ou seja, o visível. Já o submicro sendo invisível, será representado por modelos, que não retratam o está acontecendo em miniatura (BUCAT; MOCERINO, 2009; JABER; BOUJAOUDE, 2012) sendo pautados em algo concreto (modelos), que se pode visualizar, mas que se trata apenas de uma representação. Por exemplo, quando desenhamos uma molécula de hidrogênio como duas esferas unidas, isso se constitui de uma representação, um modelo para auxiliar a compreensão de algo que é abstrato e inacessível.

Finalmente, o terceiro nível é o simbólico, que justamente como o nome indica, envolve símbolos para representar átomos, bem como, letras para indicar o estado físico da entidade (GILBERT; TREAGUST, 2009), por exemplo: $\mathrm{Na}(\mathrm{s}), \mathrm{O}_{2}(\mathrm{~g}), \mathrm{H}_{2} \mathrm{O}(\mathrm{l})$, etc. As fórmulas químicas são carregadas de significados químicos específicos como, por exemplo, ao se representar $\mathrm{Na}(\mathrm{s})$ - 3 letras - estamos nos referindo ao sódio metálico ( $\mathrm{Na}$ ) no estado sólido (s), cinza, maleável, substância essa formada por inúmeros átomos de sódio unidos por ligação metálica. O nível simbólico pode ser uma representação do nível submicro, com a utilização de fórmulas ou equações (ADADAN, 2013), bem como um elo entre o macro e o submicro, no caso das equações 
químicas. E ainda, é por meio do nível simbólico (equações químicas) que podemos compreender e observar as proporções envolvidas nas transformações químicas, dando visibilidade à conservação da massa durante um fenômeno.

Nesse sentido, Gilbert e Treagust (2009) afirmam que

o primeiro tipo de representação (macro) procura representar o fenômeno como é experienciado pelos nossos sentidos (ou extensões dos sentidos); o segundo (submicro) procura trazer uma explicação qualitativa para aquele fenômeno, enquanto o terceiro (o simbólico) procura trazer uma explicação quantitativa (p.3-4, tradução nossa)

Consideramos oportuno mencionar o trabalho feito por Talanquer (2011) que amplia a compreensão dos níveis representacionais acrescentando outros aspectos como tipos de conhecimento (experiências, modelos, visualizações), dimensões (composição, energia e tempo), escalas (que vão do macroscópico ao subatômico) e abordagens (contextualizações). Consideramos que é necessário refletir e avançar nas discussões sobre os níveis, para que a compreensão da química possa se dar a partir de outras perspectivas, ampliando-se a visão triplete. Mesmo assim, nos parece bastante útil e frutífera a compreensão da química a partir dos três níveis desde que se tenha em mente possíveis ampliações posteriores, sobretudo considerando-se o Ensino de Química no nível superior.

\section{Contexto da pesquisa e a produção de dados}

Metodologicamente, optou-se pela pesquisa qualitativa, uma vez que o foco reside nos significados, que podem também abranger valores e atitudes (MINAYO, 1996). Nessa perspectiva qualitativa, em geral, as amostras são menores (alunos ou pequenos grupos) para que a análise e interpretação possam se dar em maior profundidade (MARCONI; LAKATOS, 2004), tendo 
caráter indutivo (BOGDAN; BIKLEN, 1994). Portanto, é ressaltado o significado do que se está sendo compreendido (BOGDAN; BIKLEN, 1994; MARCONI; LAKATOS, 2004).

Considerando-se essas características, a pesquisa foi conduzida em uma universidade pública paulista, durante a disciplina de PEQ II que, apesar de ser disciplina obrigatória para o curso de licenciatura de Química, pode ser cursada por qualquer aluno, dado o caráter interdisciplinar dessa instituição universitária. Durante a disciplina foram discutidos diversos assuntos relacionados à formação docente em química, sobretudo concernente aos níveis representacionais. No total, 18 alunos cursaram a disciplina, sendo que 8 deles participaram voluntariamente desta pesquisa, designados por A1 a A8 com vistas a se manter o anonimato dos participantes. Todos eles assinaram, espontaneamente e de forma voluntária, o termo de consentimento livre e esclarecido (TCLE), autorizando suas participações na referida pesquisa.

Para a coleta de dados foram utilizados os seguintes instrumentos: a questão inicial, a produção de um texto, a observação participante e um questionário autoavaliativo, todos descritos na sequência.

$\mathrm{Na}$ primeira aula do curso, os alunos responderam a uma pergunta sobre os níveis representacionais: "O que você entende por níveis de representação do conhecimento no Ensino de Química?", em que o propósito era o levantamento das ideias prévias (questão inicial). O tópico ainda foi abordado nas duas aulas seguintes, havendo a leitura e discussão de dois textos acerca de níveis representacionais: Gilbert e Treagust (2009) e Talanquer (2011). Nas aulas seguintes, outros assuntos foram desenvolvidos na disciplina, como, por exemplo, interações dialógicas, metacognição, entre outros.

A última atividade proposta no curso aos alunos tinha por objetivo a retomada de alguns conceitos desenvolvidos durante a disciplina, sobretudo quanto às transformações químicas na perspectiva dos níveis representacionais. A tarefa consistiu na proposição de uma explicação para 
a queima do metano, que compreendeu a produção de um texto pelos estudantes. Esse trabalho foi realizado em casa e com a orientação de que não deveria haver consulta a nenhum material para a sua execução, uma vez que a avaliação se daria considerando o procedimental, ou seja, a realização da tarefa da melhor forma que fosse possível a partir de seus conhecimentos prévios. Previamente à discussão coletiva, as atividades foram enviadas pelos alunos por meio do formulário on line chamado google forms ${ }^{2}$.

Durante a aula, as possíveis explicações para a queima do metano foram construídas na lousa, no coletivo e com a mediação da professora, tendo-se por base o aspecto triplete, em que foram registradas algumas falas e comentários - observação participante. Nesse momento os estudantes tinham que repensar sobre o que haviam produzido em casa (etapa metacognitiva 1). Na semana seguinte, após a aula e a discussão coletiva, os alunos responderam a um questionário autoavaliativo, que permitiu a eles refletir novamente sobre todo o processo (etapa metacognitiva 2 ).

\section{Apresentação e análise dos dados}

Para a organização dos dados, optou-se pela utilização da Análise Textual do Discurso (ATD), que consiste, basicamente, de três etapas: I) desmontagem dos textos, II) estabelecimento de relações e III) captação do novo emergente (MORAES; GALIAZZI, 2016), conforme descrito na sequência.

A desmontagem dos textos (I) consiste no processo de unitarização, cujo principal objetivo visa a elaboração das unidades de análise (UA), também chamadas de unidades de significado, que por si só devem assumir um sentido completo do sentido interpretado pelo pesquisador a partir do texto construído. Na presente pesquisa, os alunos construíram um texto com

\footnotetext{
${ }^{2}$ Trata-se de um formulário on-line, em que os alunos fazem o preenchimento e enviam para a professora de qualquer dispositivo com acesso a internet: tablets, celulares, computadores ou similares.
} 
cinco parágrafos - que constituíram o corpus textual - a fim de explicar a queima do metano. Os mesmos foram lidos várias vezes, e cinco unidades de análise foram escritas para cada aluno, sendo atribuído um título para cada uma dessas unidades, uma vez que o objetivo inicial era compreender a interpretação atribuída ao fenômeno químico, analisando-se o nível representacional considerado na explicação. Os títulos feitos a partir das UA traziam a ideia principal de cada parágrafo, uma vez que, Moraes e Galiazzi (2016) ressaltam que no processo de unitarização, os significados não precisam corresponder, explicitamente, aos demonstrados, contudo podem trazer interpretações tácitas dos textos, percebidas pelo pesquisador.

O estabelecimento de relações (II) se concretiza com o processo de categorização, em que o objetivo é a comparação e agrupamento de ideias próximas, parecidas entre as UA (MORAES; GALIAZZI, 2016).

Assim, a intenção inicial foi de se atribuir uma UA a cada um dos cinco parágrafos (ideia principal) e categorizá-la a priori em nível: macro (1); simbólico (2); submicro (3). Na figura 1 tem-se essas três categorias e suas possíveis relações:

FIGURA 1: As três categorias a priori e suas possíveis relações.

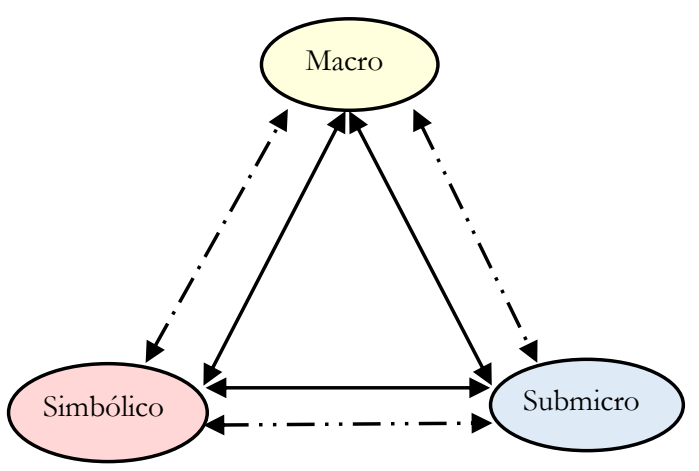

\section{Legenda:}

Mono-representacionais (elipses)

Bi-representacionais (linhas hachuriadas)

Tri-representacionais (junção das linhas sólidas)

Fonte: Autora

Desta forma, a abordagem dos alunos poderia se dar em:

- Um único nível representacional (mono-representacional): macro ou simbólico ou submicro. 
- Dois níveis representacionais (di-representacional): considera a combinação de dois níveis representacionais: macro-simbólico ou macrosubmicro ou simbólico-submicro.

- Três níveis representacionais (tri-representacional): considera todos os níveis representacionais na explicação: macro-simbólico-submicro.

Porém, a análise inicial revelou que, muitas vezes, embora algum nível seja mencionado, os alunos não propõem uma explicação considerando a formação de uma nova substância e/ou explicações de como a transformação química se procede, como o rompimento de ligações, aspectos termodinâmicos, entre outros. Então, após essa primeira categorização, foi necessário investigar se havia uma explicação acerca do fenômeno, como exemplificado na sequência.

A despeito de que muitos aspectos possam ser ressaltados pelos alunos, a principal ideia que seria desejável ser abordada por eles, como cerne de uma transformação química, refere-se, segundo Rosa e Schnetzler (1998, p.32), à abordagem de interação química entre as partículas, "indicando uma concepção dinâmica e corpuscular da matéria por parte dos (as) alunos (as)”, o que só seria alcançado se o aluno adentrasse o nível submicro, em que teríamos a explicação qualitativa do fenômeno (GILBERT; TREAGUST, 2009). Assim, na interação das partículas reagentes, teríamos as quebras de ligação nas moléculas de metano e de oxigênio com o rearranjo e formação de novas ligações, dando origem às moléculas de dióxido de carbono e de água. Por se tratar de ensino superior, também poderia se esperar algumas explicações termodinâmicas, como o aumento da entropia do universo, entre outras. Em relação ao nível macro, esperar-se-ia que os alunos considerassem a explicação com foco na interação química entre as substâncias iniciais (gases metano e oxigênio) com a formação de novas substâncias (gás carbônico e a água), neste caso, acompanhada por uma evidência de liberação de energia.

Finalmente, em nível simbólico poderia ser indicada a representada deste fenômeno químico por uma equação química: $\mathrm{CH}_{4}(\mathrm{~g})+2 \mathrm{O}_{2}(\mathrm{~g}) \rightarrow$ 
$\mathrm{CO}_{2}(\mathrm{~g})+2 \mathrm{H}_{2} \mathrm{O}(\mathrm{g})$, sendo importante ressaltar que a perspectiva de uma equação química pode se traduzir de muitos significados carregados pela forma de expressão por meio de fórmulas, a própria linguagem química.

As UA (foco do parágrafo), dos cinco parágrafos de cada aluno, permitiram a captação do emergente (III), sendo que para cada uma delas foi atribuído um texto descritor, compreendendo a "metatextos analíticos que expressem os sentidos elaborados a partir de um conjunto de textos" (MORAES; GALIAZZI, 2016, p. 53).

Analisando-se esses metatextos (descritores) obtidos, observou-se que alguns eram "indicativos" e outros "explicativos" acerca do nível envolvido, então percebeu-se a necessidade de subdividir cada uma das categorias a priori (1, 2 e 3) em mais duas denominadas emergentes - indicativa e explicativa:

(I) Categoria Indicativa (1i, 2i, 3i) - há menção ao nível representacional, mas de uma forma mais descritiva, superficial ou mais genérica.

$\rightarrow(\mathrm{E})$ Categoria Explicativa (1e, 2e, 3e) - há uma proposta de interpretação/explicação para a queima do metano em algum dos níveis conforme já discutido anteriormente.

O quadro 1 apresenta as categorias a priori, emergentes e os respectivos descritores de cada unidade de análise que emergiram a partir da leitura dos parágrafos:

QUADRO 1: Categorias e descritores

\begin{tabular}{|c|c|c|c|}
\hline CP & I/E & $\begin{array}{c}\text { Descritor (com exemplos de ideias presentes no } \\
\text { parágrafo) }\end{array}$ & Unidade de análise (UA) \\
\hline 1 & $1 \mathrm{i}$ & $\begin{array}{c}\text { Menção a aspectos do cotidiano: onde o metano é } \\
\text { liberado, obtido, encontrado, tratado, utilizações, } \\
\text { característica observável de rapidez e questões } \\
\text { ambientais como efeito estufa, biogás, aquecimento } \\
\text { global, etc. }\end{array}$ & $\begin{array}{c}\text { Descrição com cotidiano e/ou } \\
\text { ambiente }\end{array}$ \\
\cline { 2 - 5 } & 1e & $\begin{array}{c}\text { Explicação em nível macro utilizando-se dos conceitos de } \\
\text { combustível, comburente com ou sem energia associada } \\
\text { - liberada ou requerida. }\end{array}$ & $\begin{array}{c}\text { Explicação I: combustível, } \\
\text { comburente, energia. }\end{array}$ \\
\cline { 2 - 4 } & $\begin{array}{c}\text { Explicação com foco nos tipos de combustão associada - } \\
\text { completa ou incompleta. }\end{array}$ & $\begin{array}{c}\text { Explicação II: tipos de } \\
\text { combustão - } \\
\text { completa/incompleta }\end{array}$ \\
\hline 2 & $2 \mathrm{i}$ & $\begin{array}{c}\text { Menção ao nível simbólico, com foco na } \\
\text { proporção/quantidade de substâncias que reagem e }\end{array}$ & $\begin{array}{c}\text { Indica uma } \\
\text { proporção/estequiometria }\end{array}$ \\
\hline
\end{tabular}




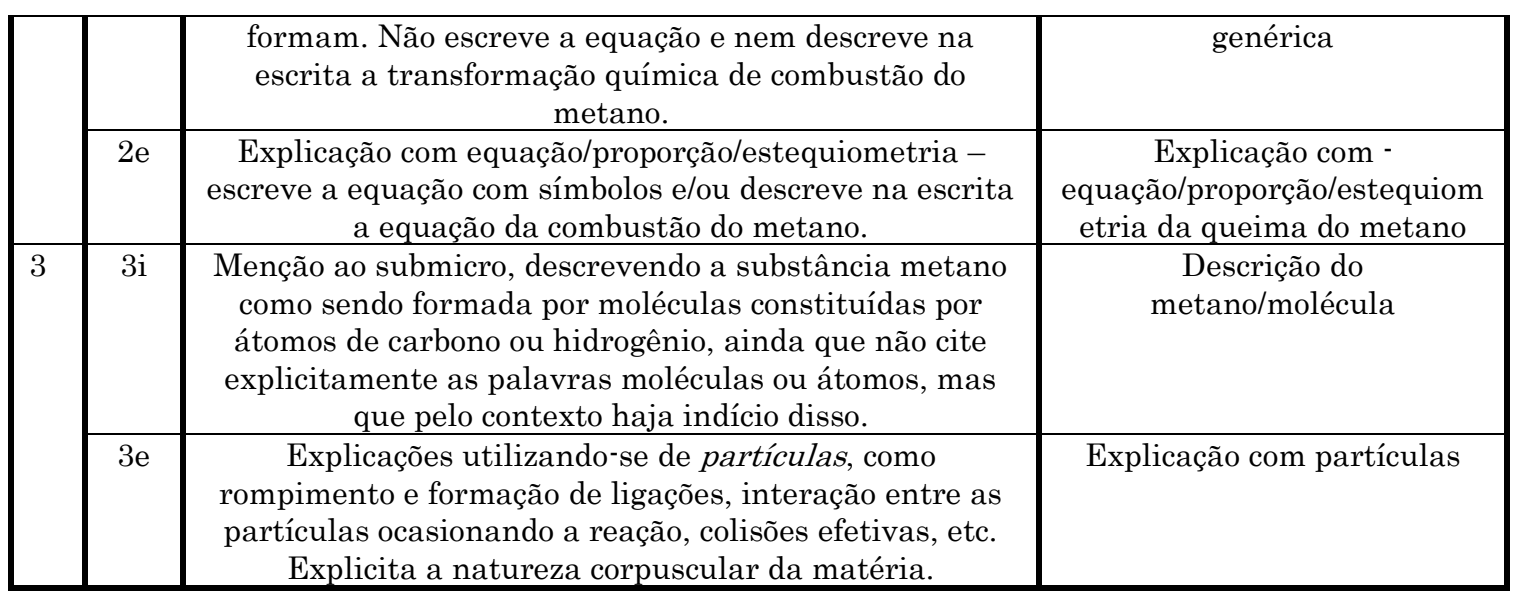

Fonte: Autora.

Como já mencionado, as UA foram elaboradas a partir da ideia central, ou seja, o foco do parágrafo, essa foi uma opção metodológica, em não se analisar somente o conteúdo, mas o significado principal que o parágrafo denota sobre a explicação proposta pelo estudante.

\section{Resultados e discussão}

Os resultados e a discussão a seguir visaram levantar elementos para se compreender como os graduandos se apropriaram dos níveis representacionais ao propor explicações para o fenômeno de queima do metano. Para isso, foram discutidas as UA (elaboradas a partir dos cinco parágrafos propostos por cada aluno), os questionários inicial (respondido no começo da disciplina) e autoavaliativo (preenchido após essa atividade metacognitiva) e as observações realizadas durante todo o processo.

\section{Análise geral das unidades de análise (UA)}

A figura 2 apresenta as prevalências de cada categoria, considerandose os cinco parágrafos propostos por cada um dos oito alunos, ou seja, num 
total de 40 parágrafos, traduzidos em 40 UA, categorizadas em macro (1i, 1e), simbólico (2i, 2e) e submicro (3i, 3e).

FIGURA 2: Prevalência geral das categorias

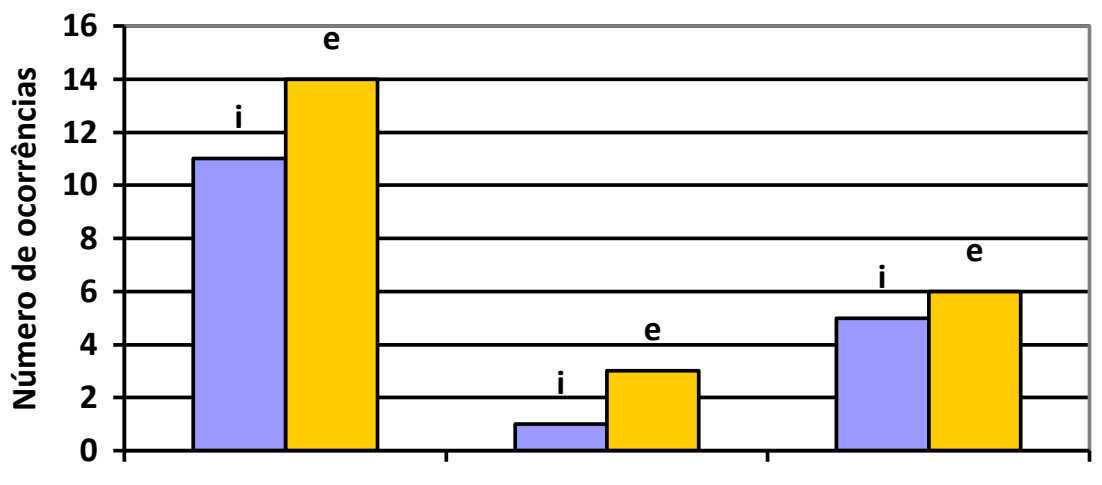

(1) Macro

(2) Simbólico

(3) Submicro

Fonte: Autora.

Primeiramente, observa-se que o nível mais prevalente nas UA foi o macro (25 UA), seguido do submicro (11 UA) e do simbólico (4 UA). Era esperado que as explicações propostas considerando o nível macro se sobressaíssem com relação aos demais (BOUJAOUDE, 1991; ROSA; SCHNETZLER, 1998), uma vez que os alunos devem partir de fenômenos que são do seu cotidiano para depois buscarem explicações no nível submicro (RAHAYU; KITA, 2010). Um exemplo pode ser observado no registro do aluno A2, sobre o metano e um possível problema com o meio ambiente:

O gás metano é liberado, principalmente, em chaminés de indústrias que, em seus processos, acabam liberando este gás, o metano. Para evitar que ocorram problemas ambientais, normalmente as chaminés ficam em constante combustão, impedindo a liberação do metano na atmosfera (categoria 1i) (A2).

No parágrafo seguinte, o estudante A2 propõe uma explicação ao fenômeno, ainda que em nível macro: 
Para que haja combustão, são necessárias três coisas: um combustível, um comburente e algo que dê a ignição, como uma faísca. Ou seja, para queimar o metano, é necessário separá-lo dos outros gases, deixando somente ele e o oxigênio, e uma faísca para ativar o sistema. O metano, por conta de sua estrutura, é facilmente consumido, liberando $\mathrm{CO}_{2}$ e água em vapor (categoria 1e) (A2).

Entretanto, embora seja importante considerar o nível macro (fenomenológico) na compreensão da transformação química de combustão, Boujaoude (1991) recomenda atenção a esse fato - aos entendimentos serem guiados apenas por aspectos visíveis - pois se assim o fazem, poderão tentar generalizar conceitos científicos partindo somente desta perspectiva, considerando poucos exemplos, que são os de seu conhecimento. Ao invés disso, Boujaoude (1991, p.701) recomenda um ensino dialógico, considerando o conhecimento prévio dos alunos onde:

Durante esse diálogo, os novos conceitos são moldados pelos já existentes para produzir um novo conhecimento pessoal; os concretos e fragmentados conceitos do senso comum se transformam em mais abstratos, ao passo que os conceitos científicos formais abstratos tornam-se mais concretos.

Também de forma geral, pode-se observar na figura 2, que um pouco mais da metade (23 UA) das unidades de análise são explicativas de acordo com os critérios adotados nesta pesquisa (1e, 2e, 3e) comparando-se com as indicativas (1i, 2i, 3i), que foram demonstradas em um pouco menos da metade, o que traz indícios de que os alunos tentaram propor explicações para a queima do metano, todavia dentre essas $23 \mathrm{UA}$, a maioria delas, 17 UA, são explicações envolvendo apenas os níveis macro ou simbólico, como pode ser observado na fala da aluna A3: 
Uma combustão completa acontece quando há gás oxigênio suficiente para conseguir consumir todo o combustível disponível, ocorrendo a transformação completa dos reagentes presentes (no caso, o combustível - metanol e o comburente - oxigênio) para os produtos (o dióxido de carbono, água e energia) (categoria 1e) (A3).

Consequentemente, apenas 6 UA foram dedicadas a nível submicro, indo ao encontro de explicações cientificamente mais aprofundadas. Um exemplo de uma explicação nesse nível particulado pode ser observado na fala da aluna A6:

Ao sofrer reação de combustão do metano (combustível) em presença de oxigênio (comburente), temos como produto: energia, gás carbônico e água. Esse processo ocorre, pois, a faísca utilizada para dar ignição aumenta a temperatura do meio, rompendo as ligações das moléculas dos reagentes, fazendo com que elas sejam recombinadas, dando a formação dos produtos acima mencionados (categoria 3e) (A6).

Nessa explicação a aluna A6 considera a interação entre as moléculas, como o rompimento e formação de ligações.

\section{Possível transição entre os níveis representacionais}

$\mathrm{Na}$ sequência, foram analisados os textos produzidos pelos oito alunos (A1 a A8), com o objetivo de se identificar os níveis representacionais demonstrados por eles para explicar a queima do metano (quadro 2) e compreender suas trajetórias individuais, segundo a abordagem feita por cada um deles. 
QUADRO 2: Níveis representacionais demonstrados

\begin{tabular}{|l|l|}
\hline \multicolumn{1}{|c|}{ Alunos } & \multicolumn{1}{|c|}{ Nível (is) abordado(s) } \\
\hline A1, A2 e A3 & Macro \\
\hline A4, A6 e A8 & Macro e submicro \\
\hline A5 & Macro e simbólico \\
\hline A7 & Macro, simbólico e submicro \\
\hline
\end{tabular}

Fonte: Autora.

Tanto na figura 2, como no quadro 2, pode-se observar que os níveis representacionais foram acessados, entretanto os alunos o fazem em diferentes níveis de aprofundamento e relações entre eles. Embora os participantes tenham um percurso universitário semelhante, às vezes eles demonstram entendimentos conceituais muito diferentes acerca das transformações químicas, o que foi observado também no trabalho de Hinton e Nakleh (1999).

Acerca dos níveis demonstrados, observa-se no quadro 2 que três alunos (A1, A2 e A3) propuseram explicações somente no nível macro (monorepresentacional), três deles (A4, A6, A8) concentraram-se nos níveis macrosubmicro (bi-representacional), o A5 no macro-simbólico (birepresentacional) e apenas A7 transitou nos três níveis (trirepresentacional). Apenas metadedos alunos propôs explicações no nível submicro (A4, A6, A7 e A8), ao passo que os demais não procuraram explicar o fenômeno químico da queima do metano considerando as interações entre as partículas. Barke et al. (2019) ressalta a importância de transitar, primeiramente, do macro para o submicro para explicar transformações químicas, uma vez que, sendo assim, a compreensão da química poderá ser mais efetiva, conforme foi observado com os alunos A4, A6 e A8. Al-Balushi (2013) afirma que o nível submicro é difícil e abstrato para os alunos e que há muita ênfase nos níveis macro e simbólico, sendo que o submicro fica em segundo plano. Herga, Cagran e Dinevski (2016) acrescentam a dificuldade 
atribuída ao nível submicro devido ao fato de que esse nível está distante da realidade dos alunos.

Assim, mesmo para alunos que não são iniciantes, como os que foram analisados, se faz necessária a retomada desses aspectos concernentes às transformações químicas, para que as explicações se pautem nos modelos e no mundo particulado. Isso vai ao encontro de várias pesquisas na área, que demonstram as dificuldades dos alunos em relação a transição dos níveis (ADADAN, 2013; CHITTLEBOROUGH; TREAGUST, 2008; GILBERT, 2008; HINTON; NAKHLEH, 1999, MOREIRA; ARROIO, 2012; RAUPP; SERRANO; MOREIRA, 2009; TALANQUER, 2011; TREAGUST; CHITTLEBOROUGH; MAMIALA, 2003; TSAPARLIS, 2009; UPAHI; RAMNARAIN, 2019). Tal fato mostra a necessidade de proposição de estratégias que permitam o repensar sobre essa compreensão de transição nos três níveis, que não se constitui em fato espontâneo conforme pontua AlBalushi (2013).

Justi, Gilbert e Ferreira (2009) sugerem que o momento de repensar é essencialmente metacognitivo e propicia ao aluno incluir aspectos nas suas hipóteses que antes não consideravam, possibilitando a modelagem dos conceitos. Transitar em todas essas formas requer prática e consciência das possibilidades que envolvem a produção desse conhecimento. Vale ressaltar que Upahi e Ramnarain (2019) analisaram livros didáticos e concluíram que o nível, predominantemente, abordado é o simbólico e praticamente inexistem representações considerando os três níveis simultaneamente, o que pode explicar também, em parte, a grande dificuldade ainda apresentada pelos alunos nos dias atuais.

Dos oito alunos, apenas 2 propuseram uma equação química para representar o fenômeno químico retratado (nível simbólico). Uma possível explicação para os alunos não terem demonstrado em maior prevalência o nível simbólico e que seria o esperado, pode ter sido a natureza da atividade em si que, na forma de texto, não facilitou a expressão de símbolos ou equações, o que pode ser considerada uma limitação deste estudo. Essa 
hipótese inicial foi confirmada ao se questionar os alunos sobre o fato, sendo que alguns pontuaram que, por se tratar de um texto, eles não acharam necessário escrever a equação, entretanto consideraram a equação química no seu raciocínio, sendo relatado por um deles (A5), que chegou a equacionar no rascunho, entretanto não apresentou no texto. Já uma outra possível explicação se dá quando Taber (2009) afirma que a simbologia química é complexa e a demanda cognitiva para compreender também. Isso porque as fórmulas químicas ou símbolos são carregadas de conceitos específicos da química.

Assim, muitas vezes a dificuldade em aprender química pode estar associada ao fato dos alunos não estarem acostumados com as representações ou não conseguirem transitar entre os níveis de representação (CHENG; GILBERT, 2009), conforme declarado pela aluna A3 referindo-se aos níveis: "Não somos ensinados a ver a química dessa forma. A primeira vez que ouvi falar nos níveis representacionais foi nessa disciplina de Prática de Ensino de Química”.

Considerando toda a problemática apresentada, a aprendizagem das transformações químicas pode ser promovida pelo ensino explícito em que o professor considere a natureza do conhecimento químico (macro, submicro e simbólico) e suas relações (JABER; BOUJAOUDE, 2012; UPAHI; RAMNARAIN, 2019), além disso, que seja retomada, ressignificada de tempos em tempos, pois como já pontuado, esse aprendizado não é espontâneo.

Outro aspecto a ser pensado e incentivado na formação inicial dos graduandos é sobre como promover a conexão com o nível submicro. Na discussão coletiva, alguns alunos citaram o fato da fuligem tê-los ajudado a lembrar que as combustões podem ser completas ou incompletas, levando-os a pensarem nas interações entre as partículas, o que Locatelli e Arroio (2017) também evidenciaram em sua pesquisa, concluindo que repensar o macro (a fuligem neste caso) pode ajudar a repensar sobre o fenômeno, adentrando no submicro. 


\section{Algumas implicações para o Ensino de Química}

Alguns pesquisadores apontam sugestões para o Ensino de Química, no que concerne aos níveis representacionais que merecem a atenção.

Cheng e Gilbert (2009) pontuam que é importante interrelacionar os três níveis para aprender química significativamente. Assim, os professores poderiam oferecer oportunidades para que os alunos tenham consciência e façam uso dos níveis representacionais em sala de aula (HINTON; NAKHLEH, 1999), sobretudo no início de novos tópicos (RAHAYU; KITA, 2010). A tomada de consciência é um aspecto metacognitivo (GIRASH, 2014) e importante na construção de significados, pois em primeiro lugar é necessário que o aluno tenha consciência que os níveis representacionais existem e podem dar um suporte no entendimento de conceitos químicos. Esse ponto foi citado, neste estudo, por parte dos alunos durante a discussão coletiva em sala de aula.

Os professores podem desenvolver formas de acessar as ideias dos estudantes sobre os níveis representacionais (HINTON; NAKHLEH, 1999). Locatelli (2018) analisou os conhecimentos prévios acerca dos níveis representacionais de alunos de graduação e observou heterogeneidade nas respostas entre os estudantes, o que implica que diferentes estratégias poderiam ser adotadas, considerando-se a individualidade de cada um dos estudantes. Desta forma, na medida em que eles constroem seus significados em aula a partir de seus conhecimentos prévios (NAKHLEH, 1992), torna-se crucial exteriorizar essas ideias.

Como transitar nos diferentes níveis requer uma habilidade visuoespacial, Raupp et al. (2009) recomendam que sejam trabalhados modelos em $2 \mathrm{D}$ e $3 \mathrm{D}$ com os alunos, conforme constataram em suas pesquisas. Nessa direção, acrescentamos aqui a necessidade de se trabalhar com imagens, desenhos e figuras que propiciará momentos de metavisualização, que refere-se a um processo metacognitivo de repensar sobre as visualizações. 


\section{Conclusões}

O nível macro é o mais demonstrado pelos alunos, mas muitas vezes, o conhecimento parece relacionado apenas a fatos do cotidiano e relações com o meio ambiente, o que consideramos importante para iniciar a compreensão, porém espera-se que haja um aprofundamento nas discussões, com explicações envolvendo o mundo particulado.

Foi evidenciada grande dificuldade na transição entre os níveis, sendo que o conhecimento acerca do triplete pode ser apropriado pelos alunos, mas demanda tempo e deve ser retomado sempre que possível, não se constituindo de um entendimento espontâneo. Isso ocorre, uma vez que os alunos não estão acostumados a pensar na química desta forma, em que transitar nos níveis é tarefa árdua a ser enfrentada pelos professores, o que ratifica a necessidade em retomar e ressignificar junto aos alunos, de tempos em tempos, com a proposição de estratégias metacognitivas, em que eles poderão se monitorar e se autorregular.

A opção metodológica do ATD utilizada nesta pesquisa mostrou-se adequada e recomenda-se para trabalhos futuros, uma vez que pode-se perceber o foco dado por cada aluno ao analisar as unidades de análise, entretanto, atenção especial deve ser dada na forma de coletar o texto junto aos alunos, para que a demonstração do nível simbólico possa ocorrer, o que pode ter sido um limite nessa pesquisa.

Recomenda-se estudos futuros que focalizem em estratégias metacognitivas que possibilitem aos estudantes, o repensar sobre os níveis representacionais, com especial atenção à compreensão das transformações químicas, sejam elas do cotidiano ou não. É importante localizar os limites e as possibilidades destas estratégias para que possam ser mais efetivas em sala de aula. 


\section{Referências}

ADADAN, E. Using Multiple Representations to Promote Grade 11 Students' Scientific Understanding of the Particle Theory of Matter. Research in Science Education, v.43, n.3. p.1079-1105, 2013.

AL-BALUSHI, S.M. The effect of different textual narrations on students' explanations at the submicroscopic level in chemistry. Eurasia Journal of Mathematics, Science \& Technology Education, v.9, n.1, p.3-10, 2013.

BARKE, H.; WISUDAWATI, A.W.; AWILAG, M.H.P.; BUCHTER, J. Acid-base and redox reactions on submicro level: misconceptions and challenge. African Journal of Chemistry Education, v.9, n.1, p.2-17, 2019.

BODGAN, R. C.; BIKLEN, S. K. Investigação qualitativa em educação: uma introdução à teoria e aos métodos. Porto Editora, 1994.

BOUJAOUDE, S.B. A study of the nature of students'understandings about the concept of burning. Journal of Research in Science Teaching, v.28, n.8, p.689-704, 1991.

BUCAT B.; MOCERINO M. Learning at the sub-micro level: structural representations. In: J.K., Gilbert, \& D.F., Treagust (Org). Multiple representations in Chemical Education (pp.11-29), 2009.

CHENG, M.; GILBERT, J.K. Towards a better utilization of diagrams in research into the use of representative levels in chemical education. In: J.K., Gilbert, \& D.F., Treagust (Org). Multiple representations in Chemical Education (pp.55-73), 2009.

CHITTLEBOROUGH, G.; TREAGUST, D. Correct interpretation of chemical diagrams requires transforming from one level of representation to another. Research Science Educational, v.38, p.463-482, 2008.

FLAVELL, J. H. Metacognitive aspects of problem solving. In L.B., Resnick (Org), The nature of intelligence (pp. 231-235). Hillsdale, N.Y., Erlbaum, 1976.

FREIRE, M.; TALANQUER, V.; AMARAL, E. Conceptual profile of chemistry: a framework for enriching thinking and action in chemistry education. International Journal of Science Education, v.41, n.3, p.1-19, 2019.

GIRASH, J. Metacognition and Instruction. In: V., Benassi, C., Overson, C. Hakala (Orgs.). Applying Science of Learning in Education. Washington, D.C.: Society for the Teaching of Psychology (pp.152-168), 2014.

GILBERT, J.K. Visualization: An emergent field of practice and enquiry in science education. In: J.K. Gilbert, M.Reiner \& M. Nakhleh (Orgs).Visualization: theory and practice in science education, (pp.3-24), 2008.

GILBERT, J.K.; TREAGUST, D.F. Introduction: macro, submicro and symbolic representations and the relationship between them: key models in chemical 
education. In: J.K., Gilbert, \& D.F., Treagust (Org). Multiple representations in Chemical Education (pp.1-8), 2009.

HERGA, N.R.; CAGRAN, B.; DINEVSKI, D. Virtual Laboratory in the Role of Dynamic Visualisation for Better Understanding of Chemistry in Primary School. Eurasia Journal of Mathematics, Science \& Technology Education, v.12, n.3, p.593608, 2016.

HINTON, M.E.; NAKHLEH, M.B. Macroscopic, and Symbolic Representations of Chemical Reactions. The Chemical Educator, v.4, n.5, p.158-167, 1999.

JABER L.Z.; BOUJAOUDE S. A macro-micro-symbolic teaching to promote relational understanding of chemical reactions. International Journal of Science Education, v.34, n.7, p.973-998, 2012.

JOHNSTONE, A. H. The development of chemistry teaching: a changing response to a changing demand. Journal of Chemical Education, v.70, n.9, p.701-705, 1993.

JUSTI, R.; GILBERT, J.K.; FERREIRA, P.F.M. The application of a 'model of modelling' to illustrate the importance of metavisualisation in respect of the three types of representation. In: J.K., Gilbert, \& D.F., Treagust (Org). Multiple representations in Chemical Education (pp.285-307), 2009.

LOCATELLI, S.W; ARROIO, A. Dificuldades na transição entre os níveis símbólico e submicro - repensar o macro pode auxiliar a compreender reações químicas?

Enseñanza de las ciencias, n. ${ }^{\circ}$ extraordinário, p.4239-4244, 2017.

LOCATELLI, S.W. Prior knowledge expressed by undergraduated students regarding to macro, submicro and symbolic levels. Em XVI International Scientific Conference, Sieldce, Polonia. Proceedings - Lifelong Learning - the present and the future, v.1, 205-209, 2018.

MARCONI, M. A.; LAKATOS, E. V. Metodologia científica. São Paulo: Editora Atlas, 2004.

MINAYO, M.C.S.O. Ciência, técnica e arte: o desafio da pesquisa social. 5. Ed. In M.C.O., Minayo (Org). Pesquisa social: teoria, método e criatividade. Editora Vozes, 1996.

MORAES, R.; GALIAZZI, M.C. Análise textual discursiva. 3. ed. Editora Unijuí, 2016 .

MOREIRA, M.H.; ARROIO, A. The complexity of representations in the chemistry teaching: an experience for atomic model. Natural Science Education, v.34, n.2, p.25-35, 2012.

NAKHLEH, M.B. Why some students don't learn chemistry: Chemical misconceptions. Journal of Chemical Education, v.69, n.3, p.191-196, 1992. 
PEREIRA, T.M.; WEISS, A.; VOGEL, M.; RECEPUTI, C.C.Uma investigação sobre os saberes docentes no processo de formação inicial da licenciatura em química: relação com as abordagens pedagógicas. Revista de Educação, Ciências e Matemática, v.8, n.2, 2018.

RAHAYU, S.; KITA, M. An analysis of indonesian and japanese students'understandings of macroscopic and submicroscopic levels of representing matter and its changes. International Journal of Science and Mathematics Education, v.8, p.667-688, 2010.

RAUPP, D.; SERRANO, A.; MOREIRA, M.A. Desenvolvendo habilidades visuoespaciais: uso de software de construção de modelos moleculares no ensino de isomeria geométrica em química. Experiências em Ensino de Ciências, v.4, n.1, p.65-78, 2009.

ROSA, M.I.F.P.S.; SCHNETZLER, R.P. Sobre a importância do conceito transformação química no processo de aquisição do conhecimento químico. Química Nova na Escola, v.8, p.31-35, 1998.

TABER, K.S. Learning at the symbolic level. In: J.K., Gilbert, \& D.F., Treagust (Org). Multiple representations in Chemical Education (pp.75-104), 2009.

TALANQUER, V. Macro, submicro, and symbolic: The many faces of the chemistry "triplet". International Journal of Science Education, v.33, p.179-195, 2011.

TREAGUST, D.F.; CHITTLEBOROUGH, G.; MAMIALA, T.L. The role of submicroscopic and symbolic representations in chemical explanations.

International Journal of Science Education, v.25, n.11, p.1353-1368, 2003.

TSAPARLIS, G. Learning at the Macro Level: The Role of Practical Work. In: J.K., Gilbert, \& D.F., Treagust (Org). Multiple representations in Chemical Education (pp.109-136), 2009.

UPAHI, J.; RAMNARAIN, U. Representations of Chemical Phenomena in Secondary School Chemistry Textbooks. Chemistry Education Research and Practice, v.20, p.146-159, 2019. 